\title{
NARRATIVAS (AUTO)BIOGRÁFICAS EN LA PEDAGOGÍA DOCTORAL. FORMAS OTRAS DE HABITAR LOS COTIDIANOS DE LA FORMACIÓN EN EL POSGRADO UNIVERSITÁRIO
}

\begin{abstract}
Porta Luis ${ }^{1}$
Aguirre Jonathan ${ }^{2}$

Resumen: El trayecto de formación doctoral en el posgrado universitario asume, en su devenir, una complejidad particular. Vida, profesión e investigación devienen en una amalgama de experiencias que el sujeto habita a lo largo de todo el proceso de formación doctoral. Desde allí, en nuestro territorio académico más próximo, comenzamos a documentar narrativamente aquellos magmas de significados y sentidos que fue asumiendo, para cada investigador en formación, su trayecto doctoral. A través de diarios (auto)etnográficos, cada tesista, fue narrando sus experiencias, sentimientos, emociones, aprendizajes y desaprendizajes vividos enel acontecer de su formación doctoral. Fuimos construyendo, deconstruyendo y habitando una pedagogía doctoral que asumió un particular carácter narrativo, colectivo, emocional y afectante para todo el grupo de investigación. En este artículo presentaremos, desde un enfoque (auto)biográfico-narrativo, relatos y experiencias de quienesatravesaron los cotidianos de la formación doctoral y se animaron a documentar narrativamente sus emociones y vivencias en diarios (auto)etnográficos. Los hallazgos que se presentan aquí dan cuenta de la potencialidad metodológica y epistémica que asume la narrativa (auto)biográficaen contextos académicos donde vida y profesión se fusionan indisolublemente.
\end{abstract}

Palabras clave: Formación de Posgrado; Pedagogía Doctoral; Investigación (auto)biográfico-narrativa; Diario (auto)etnográfico.

\footnotetext{
${ }^{1}$ Doctor en Filosofía y Ciencias de la Educación por la Universidad de Granada (España). Docente e Investigador (categoría I) del Departamento de Ciencias de la Educación de la Facultad de Humanidades (UNMdP) e Investigador Independiente del Consejo Nacional de Investigaciones Científicas y Técanicas (CONICET). Profesor Titular Regular con dedicación exclusiva de la Cátedra Problemática Educativa. Director del Centro de Investigaciones Multidisciplinarias en Educación (CIMed- UNMdP). Director de la carrera de posgrado Especialización en Docencia Universitaria (UNMdP) y del "Grupo de Investigaciones en Educación y Estudios Culturales" (GIEEC- UNMdP).

E-mail: luisporta510@gmail.com.

${ }^{2}$ Doctor en Humanidades y Artes con mención en Ciencias de la Educación por la Universidad Nacional de Rosario, Argentina. Especialista en Docencia Universitaria (UNMdP) y Profesor en História (UNMdP). Becario Interno Doctoral de CONICET. Docente e investigador del Departamento de Ciencias de la Educación de la Facultad de Humanidades/UNMdP. Es miembro del Grupo de Investigaciones en Educación y Estudios Culturales (GIEEC) y del Centro de Investigaciones Multidisciplinarias en Educación (CIMED). Secretario de la Carrera de Especialización en Docencia Universitaria de la Facultad de Humanidades/UNMdP.E- mail: aguirrejonathanmdp@gmail.com.
} 


\title{
NARRATIVAS (AUTO)BIOGRÁFICAS NA PEDAGOGIA DO DOUTORADO. OUTRAS FORMAS DE HABITAR O COTIDIANO DE FORMAÇÃO EM GRADUAÇÃO UNIVERSITÁRIA
}

\begin{abstract}
Resumo: O percurso do doutoramento na pós-graduaçãouniversitáriaassume, na suaevolução, umacomplexidade particular. vida, profissão e pesquisa tornam-se umamálgama de experiências que o sujeito habita ao longo do processo de formação de doutorado. de láemnossa próxima territórioacadêmico, narrativamente começamos a documentar esses magmas de significados e sentidos que estavaassumindo, para cada estagiário pesquisa, sua jornada de doutorado. atravésdiária (auto)etnográfico, cada tesista, estava narrando suasexperiências, sentimentos, emoções, aprendizado e desaprender viveu nos acontecimentos da suaformação de doutorado. fomosconstruindo, desconstruindo e habitar umapedagogia de doutoradoassumiuuma narrativa particular, coletivo, emocional e o caráterafetando para todo o grupo de pesquisa. este artigo apresenta, a partir de uma (auto)biográficos-narrativa abordagem, histórias e experiênciasdaqueles que passaram por todos os dias da educação de doutorado e narrativamente estimulados a documentar suasemoções e experiênciasem revistas (auto) etnográfica. os resultados aquiapresentadosperceber a narrativa metodológico e epistemológico potencial que assume o biográfica (auto) em contextos acadêmicosonde a vida eaprofissão fundir inseparavelmente.
\end{abstract}

Palavras-chave: Formação de pós-graduação; Pedagogia de Doutorado; Pesquisa (auto)biográfico-narrativa; registro auto-etnográfico.

\section{Introducción}

La formación en el posgrado universitario argentino, como en la mayoría de los posgrados internacionales, conlleva múltiples complejidades no solo de índole institucional, económica y académica, sino, particularmente, emocional y vital. Los trayectos doctorales que cada tesista emprende asumen dinámicas distintas a los itinerarios educativos previos las cuales se evidencian en diferentes aspectos: personales y subjetivos, vinculares, institucionales, curriculares (según un programa doctoral determinado), de política educativa del nivel de posgrado y más ampliamente, relativos a los 
vastos campos disciplinares del conocimiento (Mancovsky, 2016). Significa, de alguna manera, un tránsito singular que visto en retrospectiva "permite afirmar que el significado subjetivo de dicho sendero doctoral es múltiple: incluye pero excede ampliamente el conjunto de acciones estratégicas orientadas a la meta académica, constituye un plano vital de sinuosos y a veces laberínticos trayectos personales" (Flores, 2018, p.132).

En nuestro territorio académico más próximo, el Centro de Investigaciones Multidisciplinarias en Educación, radicado en la Facultad de Humanidades de la Universidad Nacional de Mar del Plata (UNMdP) en Argentina, emprendimos el apasionante viaje de documentar narrativamente aquellos significados y sentidos que asumió, para cada investigador en formación, su trayecto doctoral. Entendiendo que la tesis de doctorado no solo expone la investigación realizada sino que también da testimonio de los cambios identitarios que atraviesa el doctorando en vistas a convertirse en "autor" de los saberes que produce (Mancovsky, 2009).

El pasaje que asume la formación de posgrado de ser lector de saberes ajenos a autor de los propios fue registrado por los investigadores desde el comienzo de su labor hasta la defensa de las tesis y la consecuente titulación. Desde este espacio académico particular, fuimos construyendo, deconstruyendo y habitando una pedagogía doctoral que cristalizó un singular carácter narrativo, colectivo, emocional y afectante para todo el grupo de investigación (Porta, Aguirre y Ramallo, 2018).

En este artículo presentaremos, desde un enfoque (auto)biográficonarrativo, relatos y experiencias de quienes atravesaron los cotidianos de la formación doctoral y se animaron a documentar narrativamente sus emociones y vivencias en diarios (auto)etnográficos. Buscamos así, profundizar la indagación respecto a las múltiples y diversas experiencias educativas que acontecen en los doctorados de nuestra región. Consideramos que es desde estos hábitats experienciales y educativos que emergen formas otras de pedagogía, allí donde el sujeto crea y recrea su propio trayecto doctoral.

En el devenir del trabajo pondremos en valor la categoría iniciática depedagogía doctoral (Mancovsky, 2009, 2016; Porta, Aguirre y Ramallo, 2018) y profundizaremos la reflexión sobre la pertinencia epistémico-metodológica que asume su recuperación en la agenda educativa del nivel superior, pensando en procesos de formación un tanto más autónomos, 
emancipatorios y emocionales y que, al mismo tiempo, coloquen la propia travesía vital y profesional del sujeto en el centro de indagación.

En este contexto, el enfoque (auto)biográfico- narrativo emerge como un camino metodológico potente y alternativoque brinda la posibilidad de darle voz a los sujetos partícipes de estos viajes formativos. Los hallazgos que se presentan dan cuenta de la pertinencia metodológica y epistémica que significa la narrativa (auto)biográfica en contextos académicos donde vida y profesión se fusionan constantemente.

La arquitectura interna del artículo estará cimentada a partir de cuatro apartados hilvanados entre sí. En primer lugar esbozaremos los sustentos teóricos en relación a la construcción de una pedagogía doctoral narrativa y subjetivante en la formación del posgrado universitario. En segundo término abordaremos cuestiones ligadas a los aspectos metodológicos de la investigación y al desafío que supone incorporar como instrumento cualitativo de recolección de datos el diario (auto)etnográfico en nuestras investigaciones. El tercer apartado, representa el núcleo principal del artículo al explicitar mediante retazos narrativos los registros (auto)etnográficos de tesistas de nuestro centro de investigaciones que han concluido su doctorado y reflejan en sus trabajos un ejercicio metacognitivo de sus experiencias en el posgrado. Por último propondremos algunas conclusiones en relación a las pedagogías doctorales, las narrativas (auto)biográficas y la pertinencia político-epistémica de documentar y recuperar voces y experiencias subjetivantes en la investigación socioeducativa.

En el presente artículo, no buscamos la generalización de experiencias, sino más bien, apelamos a la profundización narrativa de los cotidianos vitales y formativos de nuestros colegas y a la visibilización de sus voces y experiencias doctorales.

\section{Hacia una pedagogía doctoral narrada que conjuga afecto y colectividad}

La categoría Pedagogía Doctoral ha sido abordada, en nuestro país, en investigaciones desarrolladas por la Dra. Viviana Mancovsky y su equipo de 
trabajo de la Universidad Nacional de Tres de Febrero (UNTREF) (Mancovsky, 2009) $)^{3}$. Advirtiendo la diversidad de problemáticas que se despliegan en torno a la formación doctoral de los sujetos que deciden seguir este nivel de posgrado académico, la autora avanzó hacia la "construcción de un escenario de reflexión posible tendiente a dar visibilidad al entramado de dimensiones de análisis que atraviesa dicho nivel formativo. Estas dimensiones comprenden diferentes aspectos: personales y subjetivos, vinculares, institucionales, curriculares, de política educativa del nivel de posgrado y más ampliamente, relativos a los vastos campos disciplinares del conocimiento" (Mancovsky, 2016, p.31).

Las primeras indagaciones en torno a la formación doctoral estuvieron signadas por la noción de relación con el saberque permitióvisibilizar la dimensión subjetiva que se traduce en una experiencia formativa singular a partir de la cual, el sujeto "se autoriza" a crear saberes nuevos argumentando académicamente el proceso de investigación que fundamenta dicha creación (Mancovsky, 2013). De allí la relevancia de concebir al trayecto doctoral como un pasaje subjetivo y pedagógico desde el cual el tesista pasa de ser lector de los saberes producidos por un tercero a constructor e intérprete de los propios (Porta, 2018).

Los estudios en torno a la formación doctoral posteriormente se centraron en la figura del director de tesis y su vinculación tanto con la práctica misma del dirigir como con el acompañamiento que se realiza al doctorando durante el proceso de formación (Mancovsky, Fabris y Cecchia, 2011). Según las autoras, aquí radica el corazón de la pedagogía doctoral. Una pedagogía que recupera su etimología primigenia del acompañar. "En este caso se trata de acompañar a un sujeto adulto que decide seguir formándose hacia la obtención del máximo grado académico" (Mancovsky, Fabris y Cecchia, 2011, p.5). Un acompañamiento que supone, en la mayoría de los casos, la puesta en juego del propio oficio de enseñar por parte de los

\footnotetext{
${ }^{3}$ El equipo radicado en la UNTREF, dirigido por la Dra. Mancovsky, ha sido pionero en los estudios sobre la formación en el posgrado nacional e internacional. Su vasta producción da cuenta de ello a partir de entrevistas a estudiantes de doctorado y a doctorados "recientes" de diversas universidades queexplicitaron las motivaciones a partir de las cuales se aventuran al doctorado, sus temores, las dificultades encontradas y las vicisitudes que atraviesan a lo largo de su experiencia formativa. Los últimos trabajos del equipo estuvieron orientados a la relación compleja, dinámica y vincular entre los directores de tesis y sus tesistas, centralmente en lo que hace al oficio propio de dirigir en el posgrado argentino.
} 
directores de tesis centrado en aspectos académico-profesionales y al mismo tiempo ligado a cuestiones vinculares, afectivas y de filiación (Porta, 2018).

El abordaje hasta aquí desarrollado entiende a la pedagogía de la formación doctoral a partir de tres grandes constelaciones interpretativas. La primera de ellas radica en el acompañamiento académico del sujeto que recrea el sentido de su formación, por un tiempo prolongado, en el cual acontece una experiencia singular de transformación subjetiva. La segunda refiere al hecho de salir del aislamiento del doctorando, hacia un devenir de los vínculos que refuerza la identidad y la pertenencia institucional en un programa institucional. Y por último, la noción de asumir la promoción de relaciones intersubjetivas basadas en la equivalencia-simetría y la gestación de condiciones para la producción de nuevos saberes habilitantes del nivel académico buscado (Mancovsky, Fabris y Cecchia, 2011; Mancovsky y Moreno Bayardo, 2015).

Nutridos con esta perspectiva epistémico-teórica, desde el Centro de Investigaciones Multidisciplinarias en Educación, recuperamos la categoría Pedagogía Doctoral dotándola de un sentido mucho más narrativo, colectivo y subjetivante. Dichas características parten de las travesías vivificadas por los investigadores del Centro en su derrotero doctoral iniciado hace más de seis años en nuestro territorio académico más próximo, la Universidad Nacional de Mar del Plata. De alguna forma, concebir a la Pedagogía Doctoral como una forma otra de pedagogía es insertar en el debate registros otros de la experiencia formativa-educativa en el posgrado universitario y repensar así, el amplio campo de la pedagogía en general (Suárez, 2018).

Consideramos, en este sentido, que es necesario “(re)enmarcar los discursos y formatos clásicos de la pedagogía a partir de reconocer la voz propia del sujeto en el proceso de transformación de lector a autor que acontece en la instancia doctoral" (Aguirre y Ramallo 2018: 256). Esto implica un (re)posicionamiento respecto a las visiones tradiciones sobre la producción científica que subyace en el posgrado universitarioen donde sujeto que investiga es, necesariamente, ajeno al proceso propio de investigación y por tanto se encuentra separado del objeto que indaga. Este (re)posicionamiento en la formación doctoral, Yedaide lo define como "práctica de (auto)arrogación de la potestad discursiva" (2018, p.155). Es decir, entender al trayecto doctoral, a la pedagogía doctoral, como una narrativa en sí misma en donde el tesista tiene la posibilidad de (auto)arrogarse la potestad de narrar 
sus experiencias, emociones, aprendizajes y desaprendizajes mediante su palabra dicha y escrita.

Así, la pedagogía doctoral deviene en productiva y performativa (Porta, 2018) puesto que al decir, al documentar narrativamente los procesos de formación, cada tesista va colocando en su relatotodo lo que es, en términos ontológicos, desde su experiencia vital y profesional (Suárez, 2017). En el diario narrativo (auto)etnográficose pone en juego la dimensión más subjetiva de la persona, allí donde aprendizaje, enseñanza, formación e investigación se amalgaman a partir de su condición inherentemente pedagógica (Porta y Aguirre, 2018).

Partiendo de los hábitats experienciales de nuestros colegas de la Universidad de Mar del Plata, habitamos una pedagogía doctoral que asume,en sí misma, una condición colectiva y afectiva en el proceso formativo y que al mismo tiempo se vuelve narrativa al documentar y registras las experiencias vitales transitadas por los sujetos (Porta y Yedaide, 2017).

La pedagogía doctoral desde la cual nos situamos, cobija la dimensión narrativa pero expande sus sentidos hacia dimensiones colectivas y afectantes en los cotidianos de formación del posgrado. En el trayecto doctoral vivido por los integrantes del grupo de investigación, tanto los colegas, como los directores han conformado una comunidad de prácticassignificativas (Wenger, 1998) de allí el carácter colectivo del proceso.

En definitiva, narrar lo acontecido en el devenir de nuestra pedagogía doctoral implicó hacer explícita en forma de relato las coreografías de aprendizaje que fuimos danzando en el transcurrir de la formación doctoral.La colectivo, afectivo y narrativo de nuestra pedagogía doctoral busca enriquecer los abordajes ya transitados por investigaciones en el campo de la educación superior, pero al mismo tiempo intenta provocar el debate sobre formas otras de caracterizar el proceso doctoral, allí donde lo biográfico-narrativo permite co-construir una pedagogía mucho más humana, humanizante y emancipatoria.

\section{Aspectos metodológicos: el desafío de incorporar el diario (auto)etnográfico en la investigación educativa}

El enfoque metodológico desplegado en nuestro trabajo asume un carácter cualitativo, hermenéutico-interpretativo y biográfico-narrativo. Nos 
situamos en el territorio de la investigación cualitativa puesto que "es una actividad localizada en cierto lugar y tiempo que sitúa al observador en el mundo. Consiste en una serie de prácticas interpretativas y materiales que hacen el mundo visible al tiempo que lo transforma" (Denzin y Lincoln, 2005, p.4). En este páramo metodológico, la investigación cualitativa "implica un acercamiento interpretativo y naturalista de las prácticas sociales desde una visión naturalista del mundo" (Denzin y Lincoln, 2015, p.154).

Inscriptos en las huellas que aún perduran del denominado "giro narrativo" (Bolívar, Domingo y Fernández, 2001) entendemos que las narrativas están presentes en todos los aspectos de la vida, abarcando desde las memorias personales hasta la literatura y la ciencia, la fotografía y el arte. Bruner indica, en este sentido, que el verbo narrar deriva de contar (narrare) y de conocer (gnarus) (Bruner, 2002). Etimológicamente, entonces, narrativa combina el relato con el conocimiento y la comprensión de lo referido (Martin, 2008).

La narrativa permite, de alguna manera, habitar las experiencias epifánicas (Denzin, 2017) en materia educativa desde una perspectiva otra que rompe con la matriz metodológica clásica de abordaje del objeto de estudio, puesto que "la narrativa es el lugar donde la existencia humana toma forma, donde se elabora y se experimenta bajo forma de una historia" (Ricoeur, 2003: 29).

La relevancia del enfoque utilizado viene dada por la ubicación del sujeto como productor de ciertos sucesos o experiencias en el contexto histórico y social a partir de la producción de su narración. De esta manera, los sujetos se hallan inscriptos doblemente en un contexto socio-histórico particular: el del momento enunciativo y el que es objeto de rememoración (Archuf, 2010). Suárez destaca la potencialidad de dicho enfoque a la hora de interpretar, en el presente, sucesos del pasado, ya que "los mismos seres humanos leen e interpretan su propia experiencia y la de los otros en forma de relato y así, nuestras acciones y la de los otros son entendidas como textos a interpretar y analizar" (2017:104).

Haciendo foco en nuestro trabajo, la (auto)etnografía presentada en forma de diario del investigador doctoral es una particular forma narrativa que encarna aspectos (auto)biográficos en relación a una etapa o experiencia particular sostenida en el tiempo. Ellis, una de las figuras fundadoras de los estudios (auto)etnográficos, sostiene al respecto que "narrativas hace 
referencia a los relatos que la gente cuenta; la manera en que organizan sus experiencias en episodios temporalmente significativos, por tanto la narrativa está presente en los registros (auto)etnográficos" (2004:195). En el binomio que ha formado Bochner que cubre muchas formas diferentes de relatos en primera persona y de narrativas de experiencias personales, la autoetnografía se configura como una forma de escritura, en la que conviven muchas especies de narrativas (auto)biográficas (Bochner y Ellis, 2016: 53).

En las tesis doctorales que se fueron tejiendo en el seno de nuestro grupo de investigación, nos animamos a narrar nuestra experiencia como estudiantes del posgrado mediante un diario autoetnográfico. Dicho diario deviene en narrativa autobiográfica (Denzin y Lincoln, 2015). Narrativa producida por el sujeto que investiga a los efectos de poder explicitar las diversas vivencias, sentimientos, interpretaciones que va registrando y sintiendo a lo largo, no solo del proceso de investigación, sino, particularmente, en el mismo trabajo de campo. Es, como argumentan los autores, un relato personal del investigador en donde explicita su propia subjetividad. "La narrativización de la vida en un autorrelato, textualiza la vida, textualiza las experiencias vitales y las convierte en un texto" (Bolívar, Domingo, Fernández, 2001, p. 31).

Relatar o narrar las experiencias en el proceso de investigación es una forma desafiante y alternativa de habitar nuestros propios sentidos y nuestras propias palabras. La escritura del diario autoetnográfico es "una forma en el espacio que prefigura el habitar de nuestras ideas" (Martínez y Bengoa, 2016, p. 47) a la vez que se transforma "en una aventura, llevada a cabo, en la ocupación del espacio” (Martínez y Bengoa, 2016, p. 48).

En el diario autoetnográfico, entendido como relato, el sujeto repiensa y reinventa sus experiencias en el campo, las interpreta tomando autoría de los hechos, y por tanto, pudiendo imaginar posibilidades de actuación futuras diferentes. Es en definitiva, un registro de experiencias, un conocimiento consciente de la singularidad de cada individuo (Bolívar, Domingo, Fernández, 2001).

A partir de narrar nuestras afecciones y emociones, que en definitiva conforman nuestra propia subjetividad, nos transformamos en narradores de experiencias y prácticas de investigación. Y así, toda narración autobiográfica ya supone en sí misma, una interpretación, construcción y 
recreación de sentidos, lecturas del propio mundo de la propia vida (Porta y Aguirre, 2018).

En el presente artículo habitaremos registros narrativos polifónicos de cuatro tesistas doctorales de nuestro Centro de investigaciones que han ido narrando los cotidianos en la formación doctoral y han podido, mediante el instrumento de diario autoetnográfico dar cuenta de sus experiencias, aprendizajes, desaprendizajes, emociones y afectaciones vividas en el devenir de su doctorado. Todos los tesistas que conforman la población del estudio han defendido sus tesis y alcanzado la titulación correspondiente. A los efectos de cumplir con los consentimientos otorgados por los participantes de la indagación y siendo coherentes con la dimensión ética que asume toda investigación cualitativa, utilizaremos la sigla RA (Registro Autoetnográfico) y el número correspondiente a cada relato sin detallar la identidad del mismo. Cabe mencionar que cada registro narrativo fue validado como instrumento de recolección de datos en las respectivas tesis doctorales anexándose una copia del mismo en loscorrespondientes anexos.

\section{Narrativas (auto)biográficas en el trayecto doctoral. una constelación de emociones, sentimientos y vínculos en el devenir de la formación de posgrado}

Sosteníamos al inicio del artículo que el trayecto doctoral asumido por cada estudiante no solo está conformado por cuestiones ligadas a los aspectos académicos propios de los programas de posgrado, sino que cada itinerario de formación asume una singularidad particular de acuerdo a las travesías biográficas de cada sujeto, a las motivaciones iniciales de tan compleja empresa, a los vínculos establecidos con sus directores de tesis, con las comunidades propias de trabajo, y por sobre todas las cosas con los ritmos que cada investigación va asumiendo en la medida se avanza con su realización. Este trayecto de formación implica aprendizajes y desaprendizajes que, al narrarlos en forma de autoetnografía, son susceptibles de poder ser objetivados, reflexionar a partir de ellos y transformar un proceso tan complejo como es un doctorado, en una experiencia pedagógica y didáctica de un carácter sumamente epifánico (Denzin, 2017). A continuación iremos habitando diferentes retazos narrativos que, agrupados en diversas temáticas, visibilizan lo educativo y lo subjetivante del trayecto doctoral, al 
tiempo que dan pistas para comprender una pedagogía de la formación en el posgrado más afectiva y humana. Intentamos en este apartado que las experiencias biográficas de los tesistas resuenen en el debate educativo y abonen los estudios sobre el nivel superior universitario.

Estamos listas hoy, mi tesis y yo, para contar quiénes somos, qué nos importa y por qué. Diría que gracias a ella soy más sabia, más comprensiva y más cuidadosa. Ella resuena en mi propia alma. Tal vez finalmente anhele lo que todo escritor: que resuene, haga olas y alguien se encuentre y se conmueva al encontrarla (RA №3)

\section{Motivaciones, huellas biográficas e inicio del viaje doctoral. "Navegando en un barquito de cáscara de nuez"4}

Al inicio de las tesis doctorales defendidas hasta el momento ${ }^{5}$ por investigadores del Centro de Investigaciones Multidisciplinarias en Educación de la UNMdP y como desprendimiento de su propio diario, se colocó un apartado titulado "Historia Natural de la Investigación". Allí, cada tesista, mediante una breve narración (auto)biográfica relata las motivaciones, deseos, pasiones que lo impulsaron a iniciar el viaje doctoral y a elegir el consecuente tema de investigación. De alguna forma, este primer ejercicio narrativo es parte de una "pedagogía de los inicios" (Mancovsky, 2017:2), en donde cada tesista inaugura la escritura de su tesis narrando sus propios itinerarios vitales que le permitieron llegar hasta allí. Itinerarios que entraman pasiones, miedos, emociones y huellas biográficas familiares,

Al principio la tesis me pareció la oportunidad de descubrir algo. Creía que era posible encontrar una respuesta que nadie había visto aun, que podía hacer un aporte a la humanidad. Hoy, tras haber transitado este camino de formación en el posgrado, sostengo que todos los descubrimientos son momentos de la (auto)comprensión y que los aportes, en todo caso, son provocaciones a pensar más allá, más acá o distinto. Pasé por todos los estados en esta extensa, abrumadora tarea de componer una tesis. Adoraba mi tema, me parecía

\footnotetext{
${ }^{4}$ Expresión extraída del Registro Autoetnográfico №2.

${ }^{5}$ Hasta abril del año 2019 se han concluido 10 tesis doctorales radicadas en el Centro de Investigaciones Multidisciplinarias en Educación de la Universidad Nacional de Mar del Plata.
} 
banal. Sentía que cualquier otro impulso a conocer algo era más interesante que el mío. Creo que eso cambió cuando convergieron finalmente saber y ser tras el sentido vital de poner nombre a las cosas. Mi papá escritor, mi mamá tan creativa, mi abuela aguda poetisa. Soy parte de un clan sensible cuyo don podría ser la palabra y la vocación por ser afectado y afectar a otros (RA №3).

Hace años cuando solo era un niño dibuje en un cuaderno a un profesor de geografía y de historia, poco supe de lo que sería en aquél momento la geografía y la historia para mí: pero así era como imaginaba ser en el futuro. Aquél lejano registro (que conservamos en mi familia) me ayudó a comprender la decisión y la elección de esta búsqueda. Más tarde ya en el transcurso de mi secundaria aquella opción se volvió irrevocable frente al impulso de buenos profesores y la elección conjunta de mis mejores amigos[...]. En ese camino me encontré con la colaboración de algunos buenos maestros y otros buenos investigadores, en especial quiénes serían mis directores y maestros en este iniciático recorrido doctoral (RA №4).

En esta primera narrativa (auto)biográficaaparecen no solo huellas familiares y emocionales, sino que también emergen cuestiones ligadas al propio plan de tesis, a los inicios de la cursada del posgrado, a las expectativas de los directores o de los propios colegas. En este sentido, el inicio del doctorado, el trabajo de campo y la redacción de la tesis es angustiante, ya que solo al final del camino, del recorrido transitado uno puede darle sentido y observar desde la integralidad todas las decisiones que ha ido tomando en pos de cumplir los objetivos de la investigación (Gessaghi, 2016). De allí que una de las tesistas, comparte en su diario (auto)etnográfico que la narrativa, en los inicios del trayecto, se convirtió en un océano en el que "navegaba en un barquito de cascara de nuez".

Al comienzo, esta incapacidad de asir ciertas ideas con la claridad necesaria para transmitirlas al papel produjoangustia y muchas noches de sueño interrumpido. La exploración de nuevos autores que nos acompañaran en la búsqueda de esa comprensión invitaba a otros que abrían nuevas propuestas. La narrativa se convirtió en un océano en el que navegaba en un barquito de cascara de nuez. Lecturas cruzadas, cinco, seis, siete libros en simultaneo, en diversos soportes (papel, laptop, tablet, e-reader...). Mi barquito se hundía. 
Sin embargo, los ecos de tantas lecturas previas que echaban tímidas raíces en Ricoeur poco a poco iban proporcionando luz. (RA N2)

Recuerdo habernos reunido [con mi director] en su casa, una tarde marplatense bien otoñal del mes de mayo y café por medio conversamos sobre los posibles temas de investigación. Más que una conversación, para mí fue una clase magistral. Defino a ese encuentro como tal porque estaba en la casa de quien me invitó a esta aventura de investigar $\mathrm{y}$ al mismo tiempo estaba oyendo $\mathrm{y}$ aprendiendo de su experiencia sobre qué temas son relevantes en una investigación doctoral, qué características deben reunir para ser potente en términos de divulgación y de aportes al campo e innumerables consejos que él los explayaba naturalmente pero para mí significaba un camino sin retorno. Yo solo escuchaba al otro lado de su escritorio, inmerso en su estudio y en la calidez que por momentos otorgan las bibliotecas, y pensaba por dentro "no lo voy a lograr, es mucho, tiene muchas expectativas (RA №1).

El inicio del programa de doctorado coincidió con mi propia inserción en el ciclo. Esa docente incipiente, no imaginaba mientras barajaba temas y posibles espacios de indagación que el trabajo de campo y la redacción del informe que implicaría la investigación la iban a interpelar de manera tan profunda con mi propia biografía, mis deseos, mis miedos y mis ganas de formarme (RA №2).

El diseño de un plan de trabajo implica un esfuerzo titánico para quienes nos asomamos a una empresa de la envergadura de un trabajo de doctorado. Nos sumergimos en lecturas teóricas en busca del punto de vista que nos oriente, barajamos posibilidades de espacios que nos reciban para explorar el tema y revisamos posibles aproximaciones metodológicas que nos guíen en la confección de las herramientas necesarias para emprender la búsqueda, fue realmente exhaustivo pero apasionante (RA №2).

La potencia de narrar el camino de la indagación y la reflexión que implicó, desde el inicio, poner en palabras o registrar en imágenes sensaciones que desafiaron al intelecto y provocaron la pulsión de las emociones convierte a la experiencia de formación doctoral en un tránsito único. La narrativa se vuelve bálsamo en el océano del posgrado. La narrativa, en este sentido, 
deviene, necesariamente en pedagogía doctoral. Una pedagogía que afecta al narrarse puesto que la narrativa (auto)biográfica es expresión subjetiva, cuenta sobre lo que pasa, lo que pasó, lo que nos pasa y es atravesada por quien narra (Souto, 2016). Como vimos hasta aquí y como veremos a continuación,

"la narrativa permite darse cuenta de las emociones y sentimientos, de las creencias e ideologías que la experiencia vivida despierta, en el recuerdo del entorno y las circunstancias, en el pasaje a la palabra dicha, en las relecturas sucesivas que permiten modificaciones, en esa hechura cuidadosa, está implicada buena parte del potencial catalítico de la narración. En esas idas y vueltas entre interioridad, distanciación, objetivación, confrontación, nueva interioridad que se despierta a la luz de lo leído; en el ir y venir de lo vivido al recuerdo, a la palabra escrita y en el volver desde otro lugar, una y otra vez, el narrar construye y deconstruye nuestro modo de estar en el mundo" (Souto, 2016:44)

\section{El posgrado y la tesis doctoral como experiencia colectiva y comunitaria}

Una de las condiciones que asume la pedagogía doctoral en nuestro territorio académico más próximo es su colectividad (Porta, 2018). Los trayectos doctorales, si bien en su gran mayoría son solitarios y poseen una cuota necesaria de soledad, también otorgan la posibilidad de transformarse en experiencias comunitarias potentes en términos pedagógicos, vinculares y profesionales. El grupo de investigación desde el cual parte el presente escrito dio cuenta en sus trabajos de lo afectante y afectivo que se vuelve el camino doctoral compartido con colegas, amigos y maestros. De allí que nos aferramos a la necesaria condición colectiva y comunitaria que debería asumir la formación en el posgrado, ya que si el proceso se emprende en solitario la complejidad del mismo puede volverse abrumadora.

Este viaje, que describí muchas veces en este tiempo como "comer un elefante" (para recordarme que tenía que proceder paso a paso frente a la monumentalidad de la tarea) estuvo poblado de compañeros, otra vez poniendo a prueba la fuerza del amor. No hay misterio más grande. Como el resto de la vida simplemente continúa, la piel también se me tatuó de dolores, miedos y 
angustias que hicieron de la tesis un trabajo nimio o un paliativo contra la desesperanza (RA №3).

Muchos colegas-amigos del Grupo de Investigación entre los que se destacan Francisco, Gladys, María Marta, Juan José, Claudia, Sonia son parte de este trabajo doctoral y les debo infinidad de sugerencias y aportes. Un ejemplo que evidencia la dimensión colectiva de la investigación fueron los intercambios que tuvimos con Claudia, quien al compartir el taller de metodología de la investigación que dicta nuestro director en la universidad, me sugirió la idea de completar un diario autoetnográfico en donde pueda poner en palabras lo que me iba sucediendo en la realización de la investigación. Ese simple consejo fue la puerta de entrada a una relación de amistad que continúa a pesar de haber terminado la tesis los dos" (RA №1)

La condición colectiva y afectiva del proceso de investigación, por lo menos en mi biografía doctoral, se constituyeron en pilares del trabajo y de mi formación doctoral. Soy consciente que no siempre el doctorado y la investigación contienen estos pilares, por tanto me siento afortunado de haber podido contar con ellos. Por la sencilla razón de que me demostraron que uno no está solo en el mundo (RA №1)

Una de las experiencias vividas que potenció la dimensión colectiva y comunitaria en la formación de posgrado de nuestro Grupo de Investigación fue la realización de un Taller de Tesis semanal ${ }^{6}$ en donde cada tesista compartía tanto los avances de su trabajo, como las complejidades con las que se topaba en su realización. Eso permitió que entre todos los participantes del espacio circularan las investigaciones y que cada uno pueda aportar desde la horizontalidad y cordialidad sus sugerencias. Por tanto, consideramos que esta narrativa colectiva que se fue forjando al calor de los encuentros semanales fue la piedra angular desde la cual los tesistas, en su derrotero de formación, no se sintieron “solos en el mundo" (RA №1).

\footnotetext{
${ }^{6}$ El taller de tesis se denominó "La investigación cualitativa en educación II y III. Reflexividad e interpretación. Trabajo de campo e interpretación de datos" a cargo del Dr. Luis Porta (UNMDP-CONICET) Carga horaria: 96 hs. 4 UVACS- Facultad de Humanidades- Universidad Nacional de Mar del Plata. Argentina.
} 


\section{Implicancia, reflexividad y trabajo de campo. El salto al vacío del viaje doctoral}

La investigación narrativa es vuelve un contexto propicio para potenciar la reflexividad del investigador y utilizarla como metodología cualitativa potente para interpretar los datos de la investigación. La narrativa se transforma en catalizador de los sentimientos, emociones, afecciones del propio investigador a lo largo de su formación doctoral. Narrar las propias sensaciones a medida que estas van sucediendo se transforma en un elemento potente de metacognición del proceso de investigación. Desde los inicios, el doctorado puede transformarse en un verdadero salto al vacío de allí la necesidad de narrarlo,

En mi caso, desde un primer momento, la tesis doctoral se volvió un constante salto al vacío en sus diferentes instancias de concreción. Salto que implicó ansiedad, nervios, inseguridades, pero al mismo tiempo inspiró confianza en mí director, en mis colegas y en mi propio trabajo de investigación. Cuando concluí la cursada del doctorado, apareció el salto al vacío hacia el proyecto de tesis. Al concluir esta instancia, emergió el salto al vacío del trabajo de campo, luego el salto hacia la interpretación y por último el vertiginoso salto hacia la defensa y posterior titulación (RA №1).

La satisfacción de la entrega y la aprobación del plan me animó a seguir, imaginar, y definir. Pero lo que no esperaba, a pesar de los temores naturales frente a lo desconocido, fue el salto al vacío que significó el trabajo de campo en sí. Una experiencia única que me atravesaría durante meses. Que a cada paso me hacía replantear la manera en que llevaba adelante esa búsqueda, que me obligó a buscar un ancla que me protegiera de la marejada y que se tradujo en la inmersión en otra experiencia que no había previsto como lo fue el ejercicio de la autoetnografía. Ese diario de campo se convirtió en un barco de papel que contenía, como podía, el impacto que los relatos de los entrevistados primero, los intercambios posteriores y el trabajo con el material implicó en mi propia identidad. La emergencia de recuerdos que me habían marcado, revivir las experiencias que me relataban, el cuestionamiento de posturas no solo frente a la profesión docente, sino a la vida misma me hacían sentir por momentos que estaba a la deriva(RA №2). 
Desde este contexto, la implicación del sujeto que investiga es parte constitutiva, ignorarlo sería ignorar el carácter humano de la investigación. La clave está en ponerla en análisis "para no quedar ciego ante su presencia al saber que se está adhiriendo de alguna forma a lo que se observa, se escucha y que ello ejerce influencias en la forma de conocer e interpretar" (Souto, 2016, p.112). Dentro del amplio proceso de investigación, en el trabajo de campo, el investigador debe hacer el ejercicio de explicitar y permitirse un acercamiento a sus afecciones, porque él mismo se afecta y es afectado por el campo. Este proceso de análisis de la implicación es una vía abierta para la investigación, es un proceso que por su singularidad, su complejidad y la relación con el contexto situacional es siempre original, inédito, irrepetible y por supuesto, escapa a todo intento de generalización de la experiencia, ya que es el propio investigador el que se implica.

El campo resultó mucho más fértil y generoso de lo que preveía, y cuando esperábamos la calma del trabajo intelectual de análisis, nos encontramos perdida en un mar de relatos, documentos, mails, imágenes y reflexiones desordenadas. Fue quizás ese diario el que logró, cómo un mapa que se dibuja mirando a las estrellas, orientar el camino para desandar y volver al puerto, para ordenar y producir un relato de identidades cruzadas en un ciclo de formación de futuros docentes. Lo que no pudo lograr es que ese marinero que zarpó fuera el mismo que regresó. Y por eso también tengo que agradecer el haberme animado a este viaje (RA №2).

Algo me pasó por primera vez en aquella entrevista, es que a medida que [la entrevistada] fue narrando su función en el programa y detallaba sus actividades, viajes, relación con las personas, me fui imaginando el paisaje y viajé yo también con ella a esas experiencias. Eso es... en cada entrevista viajo al proyecto que estudio y lo imagino. Me siento uno más en el relato, en su vida. Los sentimientos están a flor de piel en la medida que voy ingresando en la profundidad del objeto que estudio. Era consciente que debía volver al rol de entrevistador, pero me costó (RA №1)

En la sala donde realizaría la entrevista se respiraban libros. Es la primera vez que tengo tiempo solo y en silencio para observar y dejarme absorber por el clima y el contexto de la entrevista. Pude tomar conciencia de mi rol, objetivarme, hasta que subió [la entrevistada] con dos 
delicadas tazas de café y una tetera de leche para el café cortado. Todo estaba disponible para comenzar (RA №1)

Otrade las enseñanzas que mi diario deja emerger es el carácter performativo del trabajo de campo. No sólo fue un antes y un después para mí en las huellas que dicho trabajo dejara, si no que los mismos entrevistados expresan la reflexión y el impacto que el recorrido por su trayectoria les produjo en las entrevistas y en los grupos focales (RA №2).

Temo que me está costando soltar el campo, siento que siempre se puede buscar más, que me faltan datos. La figura del director se vuelve cada vez más importante, porque me marca los tiempos y los cierres. Ya es tiempo de soltar al campo y emprender la nueva etapa en la tesis (RA №1).

Habitando la última narrativa, la experiencia del campo y el trabajo interpretativo cambian la conciencia del investigador y modifican su manera de mirar los procesos sociales (Rockwell, 2009), de esta manera, no se sale indemne del trabajo de campo, el terreno siempre trasforma (Gesaghi, 2016). Transforma porque moviliza la totalidad de del investigador.

Mencionábamos al comienzo que las diversas instancias del proceso doctoral se asemejan, según los tesistas, a un salto al vacío. Si bien es cierta y pertinente la analogía, consideramos que cada etapa, a su vez, tiene una contención para evitar dicho vacío. Tanto el marco teórico, el marco metodológico, la comunidad académica que acompaña, y el acompañamiento de los directores, hacen que ese salto, en ocasiones, no esté destinado a tal vacío (Porta y Aguirre, 2018).

\section{Vínculo con el director de tesis. Oficio de enseñar y acompañar.}

Mancovsky sostiene que en la tarea del director de tesis se pone en juego no solo una relación con saber asimétrica, sino principalmente, aparecen nociones pedagógicas y didácticas a lo largo de todo el proceso de dirección. Asimismo, la autora argumenta que dicha relación entre tutorestudiante parte de un acuerdo mutuo, es decir “una elección de ambas partes que deciden trabajar juntas, desde lugares diferenciados, en el encuadre institucional de una formación doctoral" (2009:213). 
En este mismo sentido, Porta (2018) agrega que en el oficio de dirigir una tesis doctoral se manifiesta, en ocasiones, el propio oficio docente de enseñar. En dicho oficio lo vincular, lo empático y lo sensible se vuelven piezas centrales del proceso. Así lo expresan los retazos narrativos de los diarios autoetnográficos analizados,

El doctorado me permitió darme cuenta de la existencia de una verdadera didáctica del posgrado puesta en acto en primer lugar por mi director, en las reuniones, talleres e intercambios de mensajes por todas las vías que tuvimos. A esta didáctica se suman colegas y especialmente quien fuera la directora de mi primer trabajo de posgrado quien periódicamente me acercaba sugerencias, lecturas entre charlas de café en las que siempre terminaba tomando notas. $\mathrm{Y}$ de los mismos colegas con quien compartimos estos últimos tramos cuyos intercambios y sugerencias fueron invalorables. Una didáctica rizomática y horizontal que nunca me hizo sentir que este era un trabajo en solitario (RA №2).

Diversas anécdotas del trabajo de campo vienen a mi recuerdo y dan cuenta del acompañamiento sutil, sigiloso y artesanal que [mi director] ha hecho conmigo. La libertad y la confianza fueron pilares en la relación director-tesista que poco a poco fue forjando la amistad, el respeto y el cariño mutuo[...]En mi diario autoetnográfico la figura del director de tesis fue apareciendo de acuerdoavanzaba el trabajo de campo y de investigación. Desde la redacción de los capítulos ysus correcciones, hasta mensajes cercanos durante el día de trabajo en Buenos Aires,Córdoba o Necochea" (RA №1).

Mi director me aportó esa cuota de motivación, de sabiduría, de enseñanza, de tranquilidad necesaria en las múltiples vicisitudes que asume el oficio de investigar. En relación a la trasmisión de los saberes del oficio, recuerdo una conversación cuando recién comenzábamos a trabajar juntos en donde dijo que no había grandes secretos en la investigación, "se aprende a investigar, investigando y se aprende a escribir, escribiendo, no hay secretos en esto. Y por sobre todo hay que cargarse de horas silla, porque el trabajo del investigador requiere constancia" palabras que forman y que hacen crecer en la profesión (RA №4).

El vínculo forjado [con el director] trascendió lo profesional, y lo afectivo tuvo un lugar protagónico. Allí 
es donde considero que la pedagogía doctoral que pude transitar y habitar se volvió significativamente performativa. Director y tesista que permiten afectarse y dar paso a la dimensión más humana del vínculo" (RA №1).

Se desprende de las narrativas que la relación entre director y tesista, o tutor y estudiante, al ser una relación que se desarrolla en el tiempo, atraviesa momentos de muy distinta índole. Sentimientos y actitudes de: agradecimiento, admiración, crítica, enojo, insatisfacción, cansancio, agobioentusiasmo y aliento frente al esfuerzo sostenido matizan ese encuentro formativo (Mancovsky, 2009). Desde la experiencia recogida en la Universidad Nacional de Mar del Plata, la condición afectiva, vincular y horizontal que asumió la dirección de las tesis abona a una pedagogía doctoral que apueste por esas dimensiones y discuta aquellas experiencias formativas en donde los directores/tutores despliegan su rol desde la apatía, la verticalidad y el desinterés.

\section{Aprendizajes y desaprendizajes en la investigación doctoral: Lo potente del diario autoetnográfico}

La documentación narrativa de experiencias formativas $\mathrm{y}$ pedagógicas (Suárez, 2017) permite, en el nivel de posgrado dimensionar los aprendizajes y desaprendizajes que cada tesista va habitando en el devenir de su travesía doctoral. Así lo reflejan algunos de los testimonios recabados,

La importanciaradica en el carácter performativo de la escritura que nos hizo depositar en ese diario el día a día de la indagación desde el momento en que inició el doctorado y hasta que logramos sumergirnos de lleno en el análisis de los datos. Este diario además se completa con las imágenes que necesitamos registrar cuando la escritura se veía completamente cooptaba por la redacción de este informe final, que sin embargo seguía necesitando de esa instancia paralela de expresión (RA №2).

Aprendizajes y desaprendizajes de índole metodológico, epistémico y conceptual se fueron hilvanando en la escritura de cada diario colocando en la reflexividad del sujeto doctoral en el centro de la escena. El tejido polifónico resultante permite al tesista, poder observar y analizar críticamente todo el 
NARRATIVAS (AUTO)BIOGRÁFICAS EN LA PEDAGOGÍA DOCTORAL. FORMAS OTRAS DE HABITAR LOS COTIDIANOS DE LA FORMACIÓN EN EL POSGRADO UNIVERSITÁRIO

camino recorrido, desde los inicios de la cursada y la redacción del plan, hasta la confección de los capítulos finales de la tesis,

Las idas y venidas sobre la construcción de los guiones y las dificultades al poner en acto esas entrevistas nos enseñó que ningún guion es lo suficientemente comprensivo si el entrevistador no agudiza su capacidad de escucha para dejar fluir los relatos y retomar los temas en el momento indicado. Que ningún guion es lo suficientemente potente para derribar las resistencias de los docentes a volver sobre ciertos temas que consideran demasiado personales o dolorosos. Que más allá de la importancia del guion, solo es posible lograr la profundidad de la entrevista cuando se establece un vínculo con el entrevistado que demanda de una mirada atenta, de involucrarnos en el relato y de abrir nuestras propias experiencias para dar espacio al dialogo en detrimento del monólogo (RA №2).

Disfruté el grupo focal con los profesores del ISFD №35, es mas no quería terminar. Por momentos venían a mi mente los autores de la bibliografía de metodología que leí antes de visitar el instituto. Aquí me doy cuenta lo importante de la teoría en el trabajo de campo. Pude ver en la práctica lo que recomendaban los autores en el trabajo en terreno. Creo que además puse en juego todo lo que soy (RA №1).

Desde lo teórico, la escritura surge como la necesidad de poner en palabras las ideas nebulosas que iban surgiendo a medida que se avanzaba en el trabajo de campo. Además, el diario de campo nos permitió ir registrando la manera en que veíamos encarnar en los docentes aquellos marcos teóricos que nos habíamos propuesto para mirar la identidad y emerger nuevas posibilidades de abordaje, muchas de las cuales se hicieron presentes mientras otras que no encontraron su espacio en el informe, pero fueron sin embargo parte de la riqueza de esta experiencia(RA №2).

Simplemente tenía necesidad de escribir lo que estoy pensando y sintiendo luego de un enero de trabajo caluroso en Mar del Plata[...] Con el trabajo en capítulos de la tesis, me di cuenta como uno va madurando y metiéndose poco a poco en la tesis. Voy entendiendo procesos y armando en mi cabeza el esqueleto del documento final (RA №1). 


\begin{abstract}
Tres fueron los aprendizajes en estas primeras entrevistas. El primero fue aceptar lo imponderable e imprevisible que por momentos se vuelve el trabajo de campo En estos momentos es donde se pone en juego la flexibilidad del investigador al estar atento a las pistas que el propio campo va poniendo en el camino en relación al objeto de estudio. El segundo fue aceptar que los tiempos de la investigación son distintos a los míos y que los propios tiempos dentro de la entrevista son diversos y cambiantes. Mi ansiedad podría obturar los pasos del proceso o perderme la posibilidad de la re-pregunta de modo que aprender a tener paciencia fue uno de los aprendizajes más importantes que me otorgó el trabajo de campo. Ya mis tiempos dependían de los entrevistados y de las propias vicisitudes que asumiría la investigación(RA №1).
\end{abstract}

Soy parte de un orden mayor y esta tesis es parte mía. Haberla transitado equivale a haber emprendido un viaje hacia adentro también. Nunca había comprendido tanto ni leído tanto sobre los temas de la tesis; empujé el horizonte hacia todos los confines y veo con mayor nitidez ciertas formas y colores. Nunca había sentido el valor de este conocimiento como un arma para la (auto) afirmación social, la lucha por la libertad. El camino es uno solo, hacia afuera y hacia adentro (RA №3).

Desocultar el detrás de escena de la investigación y de los cotidianos de la formación en el posgrado es una de las virtudes epistémicometodológicas que asume el registro narrativo (auto)etnográfico. Comprender y objetivar los momentos de una entrevista, la confección de guiones, la realización de grupos focales, y la propia redacción del documento final, tiene una potencia subjetiva susceptible de ser compartida.

Los aprendizajes desplegados aquí, son tan solo una pincelada de lo subjetivante que se vuelve el camino doctoral. Un camino plagado de complejidades pero que encuentra intersticios desde los cuales enunciar que es posible una formación de posgrado hospitalaria y amable con una fuerte condición humana. El paso de lector a autor que vivencia el estudiante de posgrado no es lineal, y las narrativas que anteceden estas reflexiones dan cuenta de ello. La narrativa autobiográfica, en definitiva intenta visibilizar los matices que asume cada itinerario formativo. Ya que los tesistas, "al devenir escritores de sus propias travesías cuentan, de distintas maneras, su historia y sus experiencias de vida" (Arfuch, 2010:87) 


\section{Reflexiones finales. formas otras de narrar y habitar los cotidianos de la formación doctoral}

Al comienzo del escrito planteábamos las diferentes condiciones que asume la pedagogía doctoral de acuerdo el territorio académico y profesional en el que se despliegue. A pesar de su singularidad, afirmábamos, que todo espacio de formación en el posgrado nacional e internacional no solo tiene en su interior aspectos ligados a cuestiones burocráticas, políticas, rigurosidades académicas y una compleja relación con los saberes que se espera indagar. Sino que conlleva dimensiones vinculares, afectivas, emocionales y narrativas que son transitadas por cada estudiante en el devenir de su formación. Particularmente en la Universidad Nacional de Mar del Plata, desplegamos una pedagogía doctoral que se volvió afectiva, colectiva y hospitalaria.

En este contexto, el enfoque (auto)biográfico- narrativo resultó un camino metodológico y epistémico potente y alternativo que brindó la posibilidad de darle voz a los sujetos partícipes de estos viajes formativos. A partir de diarios autoetnográficos, cada tesista volvió a habitar su experiencia de formación pudiendo en el acto de narrar, objetivar su propia historia, sus motivaciones, sus ansiedades, sus miedos y deseos en el derrotero de la formación en el posgrado.

El espacio biográfico tal como observó Arfuch (2010) aportó en este sentido, una valorización de la narrativa que es inherente a la reflexión filosófica. La escritura en primera persona de las experiencias vividas por los sujetos se volvió performativa. El escribir sobre las huellas biográficas familiares, sobre el vínculo con los directores de tesis, sobre el hábitat comunitario y colectivo que acompañó la travesía doctoral, y sobre los aprendizajes y desaprendizajes acontecidos en el trayecto es en sí mismo un acto educativo, ontológico y pedagógico. Lo autobiográfico narrativo ayuda a construir la existencia de un sujeto autor de sí mismo, que se inscribe en la sociedad desde este lugar (Souto, 2016). Los relatos autobiográficos permiten conocerse más a sí mismo, conocer más a los otros, otros que nos miran, nos reflejan. Aquí radica la potencia del diario autoetnográfico en la investigación cualitativa. El registro además de ser una pieza metodológica validada a los 
efectos de reconstruir el trayecto doctoral, es potente en relación al relato propio del investigador que se configura en auto-narración subjetivante.

Desde este locus de enunciación, pensar en pedagogía(s) doctorale(s) no se trata, exclusivamente de una educación de posgrado formalizada, sino más bien se trata de maneras de educar no lineales. En estas formas otras de educar doctoralmente, interviene el oficio del profesor, los desplazamientos, los aprendizajes y desaprendizajes profesionales, el vínculo entre directores y tesistas, motivaciones y enseñanzas, procesos de filiación, la emotividad, la colectividad y la afectividad. Entender las pedagogía(s) doctorale(s) desde este entramado narrativo y biográfico implica animarnos a abrir espacios a formas otras del relato de las experiencias y los cotidianos en el posgrado, explicitando trayectorias, vidas, contextos, historia, lecturas y escrituras que hagan al doctorado un camino más ameno de transitar.

Cuando en los momentos de cerrar la tesis me invadió una sensación de vulnerabilidad aprendí algo más: esto es, nada más ni nada menos, que una declaración de lo que siento que es la vida. La tesis soy yo y todas mis creencias, lanzadas al ojo ajeno para su consideración (RA №3)

\section{Referencias}

AGUIRRE, J. y RAMALLO, F. Travesías vitales y autobiografías doctorales. Hacia una co-construcción narrativa de la Pedagogía Doctoral. Revista de Educación. v.9, n.13, p. 257-264.2018.file:///D:/Documentos/ Downloads/27448414-1-SM\%20(4).pdf

ARFUCH, L. El espacio biográfico. Dilemas de la subjetividad contemporánea. Buenos Aires: Fondo de Cultura Económica, 2010.

BOCHNER, A. y ELLIS, C.Evocativeautoethnography: Writinglives and tellingstories. Nueva York: Routledge. Ed, 2016.

BOLÍVAR A. DOMINGO J. FERNÁNDEZ CRUZ, M. La investigación biográficonarrativa en educación. Enfoque y metodología. Madrid: La Muralla, 2001.

BRUNER, J. Makingstories: law, literature, life. NY: Farrar, Straus and Giroux, 2002.

DENZIN, N. y LINCOLN, Y. Thesagehandbook of qualitativeresearch. ThirdEdition. ThoudanOaks: SagePublications, 2005.

Denzin, N. y LINCOLN Y. Manual de investigación cualitativa, IV: métodos de recolección y análisis de datos. México: Gedisa, 2015. 
NARRATIVAS (AUTO)BIOGRÁFICAS EN LA PEDAGOGÍA DOCTORAL. FORMAS OTRAS DE HABITAR LOS COTIDIANOS DE LA FORMACIÓN EN EL POSGRADO UNIVERSITÁRIO

DENZIN, N.Autoetnografía Interpretativa. RevistaInvestigación cualitativa.v.2, n.1, p. 81-90. 2017. http://dx.doi.org/10.23935/201 6/01036.

ELLIS, C. Theethnographic I: a methodological novel aboutautoethnography.Walnut Creek, CA: Altamira Press. 2004.

FLORES, G. Co-formación de la identidad doctoral: sendero de vivencias de aprendizaje en Porta, L. Aguirre, J. Ramallo, F. Pedagogía Doctoral en Educación. Investigación, Relatos y Experiencias en la Formación Doctoral. Actas del I Simposio Nacional. Mar del Plata: Universidad Nacional de Mar del Plata.2018.

GESSAGHI, V.La educación de la clase alta argentina. Buenos Aires. Siglo XXI, 2016.

MANCOVSKY, V. y MORENO BAYARDO, G. La formación para la investigación en el posgrado. Buenos Aires. Ed. Novedades Educativas, 2015.

MANCOVSKY, V. ¿Qué se espera de una tesis de doctorado? Breve introducción sobre algunas cuestiones en torno a la formación doctoral. Revista Argentina de Educación Superior. v,1. n,1. p. 201-216. 2009.http://www.untref.edu.ar/raes/documentos/

Que\%20se\%20espera\%20de\%20una\%20tesis\%20de\%20doctorado.pdf

MANCOVSKY, V. FABRIS, M. y CHECCHIA, B.Una pedagogía más allá del grado universitario: el acompañamiento de la formación doctoral. VIII Encuentro de Cátedras de Pedagogía de Universidades Nacionales Argentinas Teoría, formación e intervención en Pedagogía. La Plata. 8, 9 y 10 de agosto.2011.

MANCOVSKY, V. La dirección de tesis de doctorado: Tras las huellas de los saberes puestos en juego en la relación formativa. Revista Argentina de $\begin{array}{llllll}\text { Educación Superior. } & \mathrm{v}, \quad 6 . & \mathrm{n}, & 6 . & \mathrm{p} .50-71 .\end{array}$ 2013. http://www.revistaraes.net/revistas/raes6_conf5.pdf

MANCOVSKY, V. Un dispositivo de intervención-investigación con directores de tesis de posgrado en las Facultades de Ciencias de la Educación y de Ciencias de la Comunicación de la Universidad de Málaga, desde una pedagogía doctoral. Revista del Instituto de Investigaciones en EducaciónUNNE.v, 7. n, 9 p. 29-42. 2016. file:///D:/Documentos/Downloads/2389-7161-1PB\%20(3).pdf

MANCOVSKY, V. Por una pedagogía de "los inicios". Séptima Conferencia Latinoamericana sobre el abandono en la educación superior. Facultad de Ciencias Económicas. Universidad Nacional de Córdoba. 15, 16 y 17 de Noviembre. 2017 
MARTIN, V. A narrative inquirí intotheeffects of seriuosilness and majorsurgeryonconceptions of self and lifestory. Bristol: Unversity of Bristol. 2008.

MARTÍNEZ, C y BENGOA G. Habitares; los croquis de la palabra. Mar del Plata: Eudem, 2016.

PORTA L. y YEDAIDE, M M. Pedagogía(s) Vital(es). Cartografías del pensamiento y gestos ético-políticos en perspectiva descolonial. Mar del Plata: EUDEM,2017a.

PORTA, L. AGUIRRE, J. RAMALlO, F. Pedagogía Doctoral en Educación. Investigación, Relatos y Experiencias en la Formación Doctoral. Actas del I Simposio Nacional. Mar del Plata: Facultad de Humanidades- Universidad Nacional de Mar del Plata. 2018.

PORTA, L. y AGUIRRE, J. A autoetnografia como modo de habitar sensibilidades e sentidos da investigação narrativa. enGuedes, A y Ribeiro, T. Pesquisa, alteridade e experiência: metodologias minúsculas. São Paulo: Papirus. 2018.

PORTA, L. Pedagogía doctoral y hábitat sensoriales. Conferencia Inaugural del I Simposio sobre Pedagogía Doctoral: Investigación, relatos y experiencias en la formación doctoral. Facultad de Humanidades- UNMdP. Mar del Plata 26 y 27 de marzo. 2018

RICOEUR, P. El conflicto de las interpretaciones. Ensayos de hermenéutica.Buenos Aires: Fondo de Cultura Económica. 2003.

ROCKWELL, E. La experiencia etnográfica. Buenos Aires: Paidós. 2009.

SOUTO, M. Pliegues de la Formación. Sentidos y herramientas para la formación docente. Rosario: Homo Sapiens. 2016.

SUÁREZ, D. Docentes, relatos de experiencia y saberes pedagógicos: La documentación narrativa de experiencias en la escuela. Investigación $\begin{array}{lllll}\text { Cualitativa, } & \text { v, } & 2 . & \mathrm{n}, 1, & \text { p. }\end{array}$ 60.2017.https://ojs. revistainvestigacioncualitativa.com /index.php/ric/article/view/58

SUÁREZ, D. Pedagogía Doctoral: lxs tesistas y la tesis. El proceso de transformarse de lector en (co)autor. Conferencia principal I Simposio sobre Pedagogía Doctoral: Investigación, relatos y experiencias en la formación doctoral. Facultad de Humanidades- UNMdP. Mar del Plata 26 y 27 de marzo. 2018. 
NARRATIVAS (AUTO)BIOGRÁFICAS EN LA PEDAGOGÍA DOCTORAL. FORMAS OTRAS DE HABITAR LOS COTIDIANOS DE LA FORMACIÓN EN EL POSGRADO UNIVERSITÁRIO

WENGER, E. Cominunidades de práctica. Aprendizaje, significado e identidad. Cambridge UniversityPress. 1998.

Recebido em 29 de abril de 2019.

Aceito em 30 de maio de 2019. 